\title{
Sharp Pain
}

National Cancer Institute

\section{Source}

National Cancer Institute. Sharp Pain. NCI Thesaurus. Code C101179.

A sensation of discomfort or distress that is distinct and intensely focused. 